\title{
Comparative study of efficacy of nifedipine, nitroglycerin dermal patches and isoxsuprine as tocolytic agents in suppression of preterm labour 1-year study at navodaya medical college hospital and research centre Raichur
}

\author{
Rita D., V. Haripriya*
}

\begin{abstract}
Department of Obstetrics and Gynecology, NMCH and RC, Rajiv Gandhi University of Health Sciences, Karnataka,
\end{abstract} India

Received: 07 May 2021

Revised: 03 June 2021

Accepted: 04 June 2021

\author{
*Correspondence: \\ Dr. V. Haripriya, \\ E-mail: rohithkumar1808@gmail.com
}

Copyright: ( ) the author(s), publisher and licensee Medip Academy. This is an open-access article distributed under the terms of the Creative Commons Attribution Non-Commercial License, which permits unrestricted non-commercial use, distribution, and reproduction in any medium, provided the original work is properly cited.

\begin{abstract}
Background: Tocolytic agents are used to reduce preterm deliveries. Very few studies documenting the comparison of tocolytic agents viz. nifedipine, nitroglycerin dermal patches and isoxsuprine. Other drugs are not used due to their adverse effects. Objective was to study and compare the safety efficacy of nifedipine, nitroglycerin dermal patches and isoxsuprine as tocolytic agents in suppression of preterm labour 1 year study.

Methods: This was a prospective case control study was conducted for a period of 1 year. Total 90 cases selected to study were randomly distribute in to three treatment groups viz. A, B, and C nifedipine, nitroglycerin and isoxsuprine respectively. Subjects in all three groups were evaluated for maternal pulse rate, palpitation uterine contractions and fetal heart rate in order to assess efficacy of each drug under investigation.

Results: There was no statistically significant difference in age of woman's in three different groups. Among (100\%) subjects, majority of the cases i.e. (27.8\%) primi gravida followed by multi (72.2\%). Side effects of nifedipine was less when compared to nitroglycerine dermal patch and isoxsuprine i/v/o of headache $(8.9 \%)$, nausea (1.1\%), vomiting $(1.1 \%)$, tachycardia $(3.3 \%)$, palpitation $(3.3 \%)$, hypotension $(1.1 \%)$. side effects were statistically significant different between the treatment groups. There was no statistically significant difference with respect to APGAR score at 1 minute and 5 minutes.

Conclusions: Oral nifedipine was found to be superior and efficacious as tocolytic agent as compared to transdermal nitroglycerin and intravenous isoxsuprine.
\end{abstract}

Keywords: APGAR score, Isoxsuprine, Nifedipine, Nitroglycerin, Preterm labour

\section{INTRODUCTION}

According to WHO, onset of labour before 37 completed weeks (259 days) counting from the first day of last menstrual period, is termed as Preterm labour. While the exact mechanism of preterm labour remains unclear, it is most frequently associated with either a pathology causing uterine contractions or early/untimely initialization of normal physiological uterine contractions, leading to preterm deliveries. ${ }^{1}$ Preterm represents a serious public health problem in $7-12 \%$ of the pregnancies and results in up to $70-80 \%$ of neonatal morbidity and mortality. ${ }^{2}$ Practically, survival outcomes are better in births after 34 weeks of gestation, because of rapid advancements in fetomaternal medicine during the last few years.

Use of tocolytics is among the best methods to reduce morbidity and mortality associated with preterm. They cause partial uterine relaxation and hence help in prolonging the pregnancy for at least 2-3 days and thus, 
providing adequate time for administration of corticosteroids which would help in lung maturity and prevent respiratory distress syndrome in newborns. Over the time, numerous tocolytics with varying mechanism of actions have been used to delay labour. Use of drugs like isoxsuprine, ritodrine, nifedipine are reported to cause adverse effects like pulmonary oedema, arrhythmia and myocardial ischemia in mothers and neonatal hyperglycemia, hypokalemia, hypoglycemia and paralytic ileus in the fetus. ${ }^{3}$

Nifedipine which works by blocking the voltage dependent calcium channels in the plasma membrane, increasing calcium efflux from cell and decreasing intracellular free calcium, thus causing inhibition of calcium dependent MLCK (myosin light chain kinase) phosphorylation and myometrial relaxation, is the most commonly used tocolytic drug. ${ }^{4}$

Another emerging drug which is used as a tocolytic is nitroglycerin, worldwide known as glyceryl trinitrate (GTN). It is a low molecular weight nitrate which is highly volatile in nature and also known as nitro vasodilator. Nitroglycerin is a drug with high first pass inactivation in liver. The active substance is rapidly metabolized in the liver by a glutathione dependent organic nitrate reductase. To avoid it, transdermal use of the drug is beneficial so that sufficient level of drug reaches plasma level. ${ }^{2}$ It delays the delivery by relaxing the smooth muscles of uterus and also improve blood flow to the uterus and placenta. It has high first pass metabolism and is rapidly metabolized in liver. But its transdermal use helps in preventing this and ensures that sufficient amount of drug reaches the plasma.

Beta adrenergic receptor blocking agent isoxsuprine and nifedipine, a calcium channel blocking agent is the most widely used tocolytic agent in India.

Nifedipine, nitroglycerin dermal patches and isoxsuprine are effective tocolytic drugs and very few studies have been done in India comparing the safety and efficacy of these three tocolytic drugs. Hence our study aims to study the safety and comparative evaluation of efficacy of oral nifedipine, transdermal nitroglycerin patches, and isoxsuprine as tocolytic agents in the management of preterm labour.

\section{METHODS}

This is a prospective case control study conducted for the period of 1 year Ethical Committee approval taken. The study subjects are women who were admitted in the labour ward with the diagnosis of preterm labour from January 2020 to December 2020 in Navodaya medical college hospital and research centre, Raichur.

\section{Inclusion criteria}

Subjects with gestational age between 28 and 36 weeks, singleton pregnancy, at least four contractions during
20 minutes or eight contractions during 60 minutes plus with no previous administration of tocolytic.

\section{Exclusion criteria}

Medical disorders patients, subjects with obstetric complications like hypertensive disorders of pregnancy, antepartum haemorrhage, ruptured membranes, dilatation of $>4 \mathrm{~cm}$, foetal complications like chorioamnionitis, IUGR, congenital anomaly, foetal distress and multifoetal gestation.

A sample size of 90 patients (30 in each group) was considered. A written informed consent was obtained from all participants who were fully informed about the study. Eligible women (90) enrolled in to the study were randomly grouped into A, B and C. Group A $(n=30)$ : subjects in group A were administered with $30 \mathrm{mg}$ oral nifedipine initially followed by $10 \mathrm{mg}$ at 8 hourly intervals for 48 hours. Drug dose was gradually tapered every 24 hours and then stopped. If contractions persisted at 90 minutes, the first $10 \mathrm{mg}$ dose was started at the same time. Headache and hypotension were the side effects. Drug was stopped if there was persistent hypotension. Group B $(n=30)$ : subjects in group $B$ was applied a transdermal nitroglycerin patch, nitroderm, which delivers $5 \mathrm{mg}$ nitroglycerin over twelve hours and it was applied to the woman's abdomen. If contractions persisted at the end of one hour an additional patch was applied. No more than 2 patches were worn simultaneously $(10 \mathrm{mg})$. At the end of 12 hours these was replaced by a fresh patch. Mild headaches were treated with paracetamol. Patches were remained in place for 12 hours after the contractions had ceased. Group $C(n=30)$ : subjects in group $C$ will be given injection isoxsuprine $40 \mathrm{mg}$ intravenously infusion for 48 hours. Patients who responded were switched over to 20 $\mathrm{mg}$ oral retard tablet given 12 hourly as maintenance therapy for 1 week. Side effects like palpitations, tachycardia, hypotension, were more with the isoxsuprine when compared to above tocolytics.

In all the three groups subjects were strictly monitored for uterine contractions, maternal pulse rate, palpitation and fetal heart rate. In case of any serious side effects as progression of labour, the respective drug was stopped.

\section{Statistical analysis}

Data were entered in the excel spread sheet and analysed using SPSS (Statistical Package for Social Sciences) version 20. ANNOVA test (chi-sqaure test) was used to test the significant results between the variable groups.

\section{RESULTS}

A total of 90 women were evaluated (30 women in each group).

Table 1 shows the distribution of the subjects based on age. Out of $90(100 \%)$ subjects, $49(54.4 \%)$ were aged between 
20 to 25 years followed by 35 (38.9\%) subjects aged 26 to 30 years. Chi-square test showed no statistical significant association with respect to age $\left(\chi^{2}=1.34 ; \mathrm{p}=0.85\right)$.

Table 1: Distribution of the subjects based on age.

\begin{tabular}{|lllll|}
\hline Drugs & $\begin{array}{r}\mathbf{2 0 - 2 5} \\
\text { years }\end{array}$ & $\begin{array}{l}\mathbf{2 6 - 3 0} \\
\text { years }\end{array}$ & $\begin{array}{l}\mathbf{3 0 - 4 0} \\
\text { years }\end{array}$ & $\begin{array}{l}\text { Total cases } \\
\text { in each } \\
\text { group }\end{array}$ \\
\hline Nifedipine & $\mathbf{1 6 . 7 \%}$ & $13.3 \%$ & $3.3 \%$ & $30(100 \%)$ \\
\hline Nitroglycerine & $20.0 \%$ & $12.2 \%$ & $1.1 \%$ & $30(100 \%)$ \\
\hline Isoxsuprine & $17.8 \%$ & $13.3 \%$ & $2.2 \%$ & $30(100 \%)$ \\
\hline
\end{tabular}

Chi-square value- $1.34, \mathrm{p}$ value- 0.85

Table 2: Mean age distribution of the subjects.

\begin{tabular}{|lllll|}
\hline Groups & N & Min. & Max. & Mean \pm SD \\
\hline Nifedipine & 30 & 21 & 36 & $26.00 \pm 3.629$ \\
\hline Nitroglyclerin & 30 & 20 & 31 & $25.13 \pm 2.956$ \\
\hline Isoxsuprine & 30 & 21 & 36 & $25.87 \pm 3.540$ \\
\hline
\end{tabular}

Table 2 shows mean age of nifedipine was $26 \pm 3.62$ followed by isoxsuprine- $25.87 \pm 3.54$ and nitroglycerin group- $25.13 \pm 2.956$.

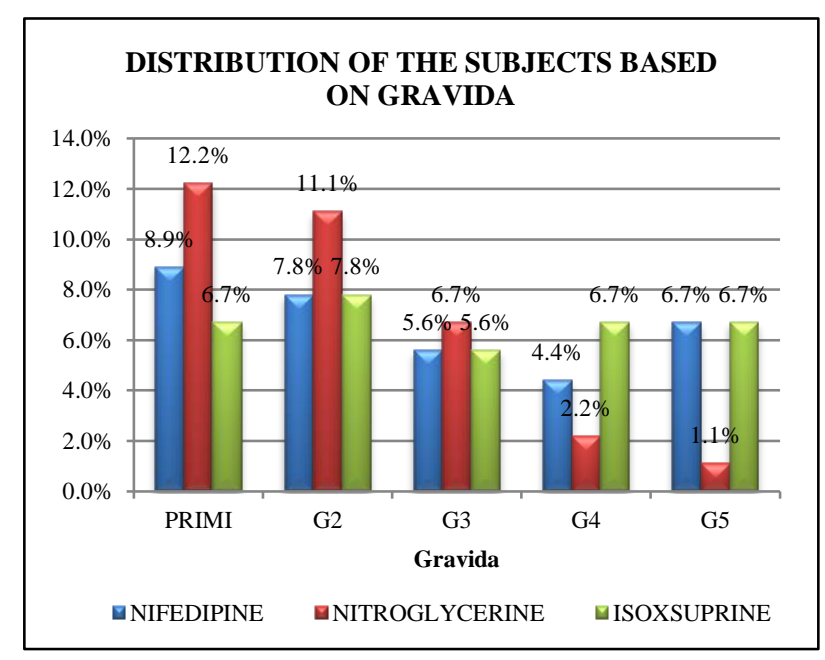

Figure 1: Distribution of the subjects based on gravida.

Figure 1 shows among $90(100 \%)$ subjects, majority of the study subjects i.e. $25(27.8 \%)$ had $\mathrm{G}_{1}$ gravida followed by 24 (26.7\%), 16 (17.8\%), 12 (13.3\%), 13 (14.4\%) had $\mathrm{G}_{2}$, $\mathrm{G}_{3}, \mathrm{G}_{4}$ and $\mathrm{G}_{5}$ type of gravida. Furthermore there was no statistically significant difference $\left(\chi^{2}=8.24 ; p=0.41\right)$ in distribution of study gravida type of study subjects and treatment groups (Table 3).

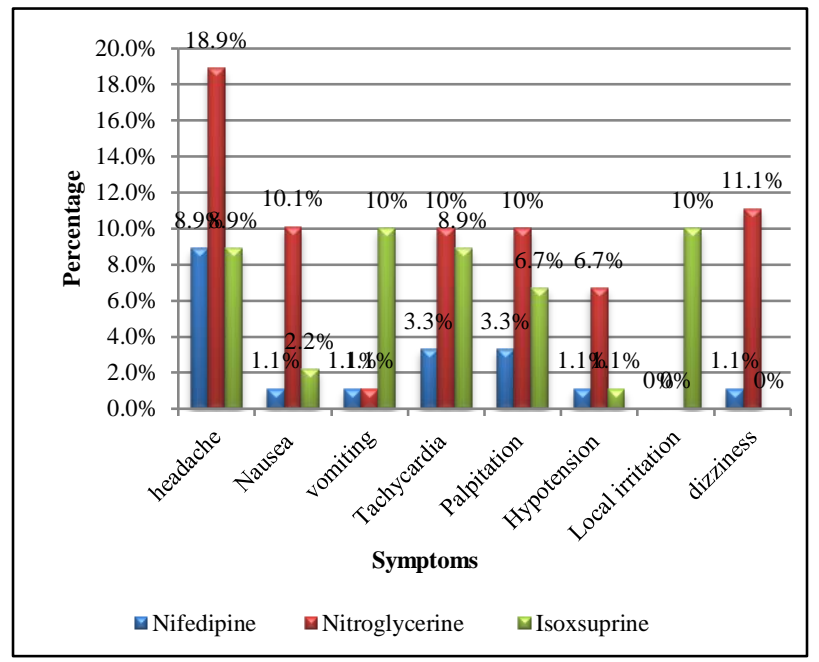

Figure 2: Distribution of the subjects based on symptoms

Figure 2 shows headache was present in 33 (36.7\%) subjects out of which $17(18.9 \%)$ belonged to nitroglycerin group. Similarly nausea- $9(10 \%)$, vomiting- $9(10 \%)$, tachycardia- $9(10 \%)$, palpitation- $9(10 \%)$, hypotension$6(6.7 \%)$, local irritation- $9(10 \%)$ and dizziness-10 $(11.1 \%)$ were present higher in nitroglycerin group as compared to nifedipine and isoxsuprine. Chi-square test showed statistical significant association with respect to headache $\left.\chi^{2}=7.75 ; \mathrm{p}=0.021\right)$, nausea $\left(\chi^{2}=10.96 ; \mathrm{p}=0.004\right)$, vomiting $\left(\chi^{2}=13.25 ; \mathrm{p}=0.001\right)$, hypotension $\left(\chi^{2}=9.6\right.$; $\mathrm{p}=0.008)$, local irritation $\left(\chi^{2}=20.0 ; \mathrm{p}=0.00\right)$, and dizziness $\left(\chi^{2}=18.84 ; \mathrm{p}=0.00\right)$.

Table 3 shows mean number of hospital stay in nifedipine, nitroglycerin, and isoxsuprine was 11.57 \pm 4.313 , $11.23 \pm 4.313$, and $12.13 \pm 4.091$ respectively. However, there was no statistically significant difference $(\mathrm{p}=0.70)$ was observed between hospital stay and treatment groups

Figure 3 shows comparison of APGAR score at 1 and 5 minutes. APGAR score was higher in isoxsuprine group at 1 and 5 minutes- $7.23 \pm 1.223$ and $8.40 \pm 1.429$ respectively. ANOVA test was applied to compare the APGAR scores among the groups at 1 and 5 minutes. ANOVA test showed no statistical significant difference with respect to APGAR score at 1 minute $(\mathrm{p}=0.92)$ and 5 minutes $(\mathrm{p}=0.43)$ among the groups.

Table 3: Comparison of no of days prolonged among the groups using ANOVA.

\begin{tabular}{|lllllll|}
\hline Groups & $\mathbf{N}$ & Minimum & Maximum & Mean & Std. deviation P value \\
\hline Nifedipine & 30 & 6 & 20 & 11.57 & 4.313 & 0.70 \\
\hline Nitroglycerin & 30 & 5 & 20 & 11.23 & 4.313 & \\
\hline Isoxsuprine & 30 & 7 & 20 & 12.13 & 4.091 \\
\hline
\end{tabular}




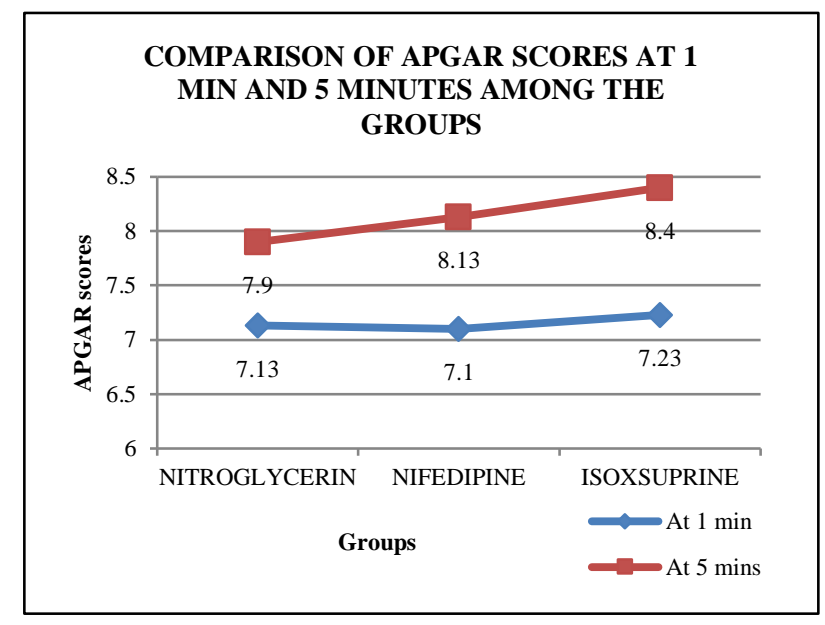

Figure 3: Comparison of APGAR scores at 1 minute and 5 minutes among the groups using ANOVA.

\section{DISCUSSION}

Despite advances in perinatal medicine the incidence of preterm birth has increased since the early 1980 . Neonatal morbidity and mortality increase with preterm delivery. For example, the incidence of severe intraventricular hemorrhage decreases after 27 weeks and rare after 32 weeks and incidence of necrotizing and respiratory distress syndrome also decreases with advancing gestational age. Primary goal of tocolysis is to have some time to administer antenatal corticosteroid which leads to reduce neonatal morbidity and mortality. A number of tocolytics have been advocated for the treatment of threatened preterm labour in order to delay delivery.

In the study conducted by Rekha et al, headaches were exclusively seen in nitroglycerine group in $100 \%$ subjects, isoxsuprine group $100 \%$. So, our study is comparable with the above mentioned study as headache (18.9\%) was exclusive side effect of nitroglycerine group. ${ }^{3}$

In contrast, in a meta-analysis in 2002, Duckitt et al, five clinical trials, which have been performed on nitroglycerine effects for delaying delivery and improvement of neonatal outcome in cases of threatened preterm labour, were evaluated. ${ }^{6}$

Though our study did not show statistical significance but it showed reported improvement in neonatal outcome and delaying delivery. The authors concluded that at the present time, evidence is not enough to support routine use of NO donors for treatment of threatened preterm labour.

Nitric oxide donors, such as nitroglycerine, have been used to relax the uterus. There was reduction in number of deliveries less than 37 weeks with nitric oxide donors when compared with alternative tocolytics. Side effects were reduced in women who received nitric oxide donors rather than other tocolytics. However, women were significantly more likely to experience headache when nitric oxide donors had been used. ${ }^{6}$
Amorim et al enrolled 50 patients and compared the effect of oral nifedipine and NTG as a tocolytic agent. They found the rate of preterm delivery in the first 48 hours was $15.4 \%$ and $12.5 \%$ respectively in nitroglycerine and nifedipine groups. ${ }^{7}$

In our study, headache was the most common side effect found in all the three tocolytic groups treated, majority of the subjects showed headache in $18.9 \%$ subjects treated with nitroglycerine followed by $8.9 \%$ subjects treated with nifedipine and isoxsuprine treated.

In Rowlands et al study showed beneficial effects of transdermal nitroglycerine for postponing delivery in preterm labour. ${ }^{8}$ Leszczynska-Gorzelak et al evaluated the effect of transdermal nitroglycerine on 30 pregnant women with the complain of preterm labour who were in their 27 to $34^{\text {th }}$ week of their pregnancy and the study results revealed that reduction in uterine contractions in all women without any effects on fetal heart rate and cardiotocography. ${ }^{9}$

In our study, nitroglycerine could arrest uterine contractions significantly better than nifedipine and the adverse effects were minimal. At the same time, NICU admission and duration of NICU stay was same for both nitroglycerine and nifedipine. The duration of NICU stay was more in isoxsuprine when compared to nitroglycerine and nifedipine. Although not statistically significant, this may have influence on neonatal outcomes study, ritodrine and trans-dermal glyceryl trinitrate were compared for their effects on fetus and mother. ${ }^{10}$ They reported that with the therapeutic amount that is necessary for tocolysis, NG has minimal effects on blood pressure, pulse rate and fetal heart rate, and these effects are less than vascular adverse effects of intravenous ritodrine. Therefore, nitroglycerine is a safer drug for women with preterm labour.

But this is in contrast to our study results where, nitroglycerine had more side effects when compared to nifedipine and isoxsuprine. Isoxsuprine had minimal side effects on tachycardia, palpitation, hypotension and had low side effects like headache, nausea, vomiting, local irritation and dizziness.

In all the three tocolytic administered agents all the neonates had mean Apgar score of $>7$ at 5 minutes and thus did not required resuscitation. This is in contrast with the study of Rekha et al, where $16 \%$ of the neonates in isoxsuprine group had Apgar score $<7$ at 5 minutes and thus required resuscitation while only $2 \%$ neonates in transdermal nitroglycerine patch group had Apgar score $<7$ at 5 minutes and required resuscitation. In the study of Sharma et al and Kashanian et al the adverse effects of nifedipine and nitroglycerine groups were similar. Fetal outcomes like Apgar score and adverse effects were better in nifedipine group. Also, the neonatal intensive care unit (NICU) admission and duration of NICU stay were less in the nifedipine group. ${ }^{11,12}$ 


\section{CONCLUSION}

Early detection of preterm labour and treatment can prevent prematurity, low birth weight, respiratory distress syndrome, perinatal morbidity and mortality. Study delineated that nifedipine shows less adverse effects when compared to nitroglycerine dermal patch and isoxsuprine showed more adverse effects. Hence, nifedipine could be considered as the choice of tocolytic agent for all preterm labour patients. To the best of our literature knowledge this is the preliminary report where safety and efficacy of three tocolytic agents viz. nifedipine, nitroglycerine, and isoxsuprine was compared.

\section{ACKNOWLEDGMENTS}

Author would like to thank Dr. Rita D. Professor and HOD Department of obstetrics and gynecology Navodaya medical college hospital and research centre Raichur and Dr. B. Vijyachandra Principal, NMC, Raichur for giving me an opportunity to conduct this study.

\section{Funding: No funding sources}

Conflict of interest: None declared

Ethical approval: The study was approved by the Institutional Ethics Committee

\section{REFERENCES}

1. Hubinont C, Debieve F. Prevention of preterm labour: 2011 update on tocolysis. J Pregnancy. 2011;2011:941057.

2. Banerjee BD, Mustafa MD, Sharma T, Tyagi V, Ahmed RS, Tripathi AK, et al. Assessment of toxicogenomic risk factors in etiology of preterm delivery. Reprod Syst Sex Disord. 2014;3(2):1-0.

3. Rekha S, Pooja G, Patel ML, Shipra C, Reshu A. Clinical evaluation of transdermal nitroglycerine in preterm labor in tertiary care teaching hospital in North India. Int J Sci Res Pub. 2012;2(3):7.
4. Kaur M, Goel B, Singh J. Comparative study of Nitroglycerine dermal patch versus nifedipine in the management of preterm labour. Int $\mathrm{J}$ Reprod Contracept Obstet Gynaecol. 2018;7(10):4244-8.

5. Jeyabalan A, Caritis SN. Pharmacologic inhibition of preterm labor. Clin Obstet Gynecol. 2002;45(1):99113.

6. Duckitt K, Thornton S. Nitric oxide donors for the treatment of preterm labour. Cochrane Database Syst Rev. 2002;3(3):CD002860.

7. Amorim MM, Lippo LA, Costa AA, Coutinho IC, Souza AS. Transdermal Nitroglycerine versus oral nifedipine administration for tocolysis: a randomized clinical trial. Revista Brasil Ginecol Obstet. 2009;31(11):552-8.

8. Rowlands S, Trudinger $\mathrm{B}$, Visva-Lingam $\mathrm{S}$. Treatment of preterm cervical dilatation with glyceryl trinitrate a nitric oxide donor. Aust N Z J Obstet Gynaecol. 1996;36(4):377-810.

9. Leszczynska-Gorzelak B, Laskowska M, Marciniak B, Oleszczuk J. Nitric oxide for treatment of threatened preterm labor. Int $\mathbf{J}$ Gynaecol Obstet. 2001;73(3):201-6.

10. Black RS, Lees C, Thompson C, Pickles A, Campbell S. Maternal and fetal cardio vascular effects of transdermal glyceril trinitrate and intravenous ritodrine. Obstet Gynecol. 1999;94(4):572-6.

11. Sharma N, Rani S, Huria A, Chawla D. Oral nifedipine versus nitroglycerine patch for tocolysis in preterm labour. Int $\mathbf{J}$ Reprod Contracept Obstet Gyenecol. 2019;8(1):174-8.

12. Kashanian M, Zamen Z, Sheikhansari N. Comparison between nitroglycerine dermal patch and nifedipine for treatment of preterm labor: a randomized clinical trial. J Perinatol. 2014;34(9):683-7.

Cite this article as: Rita D, Haripriya V.

Comparative study of efficacy of nifedipine, nitroglycerin dermal patches and isoxsuprine as tocolytic agents in suppression of preterm labour 1 year study at Navodaya medical college hospital and research centre Raichur. Int J Reprod Contracept Obstet Gynecol 2021;10:2806-10. 